IVCi, IVC-CI, and group $\mathrm{N}$ were not statistically significant $(\mathrm{P}>0.05)$. Area under curve (AUC) of IVC-CI to assess volume responsiveness in geriatric hip fracture patients was $0.80 \pm 0.08$ (0.65-0.95, $\mathrm{P}=0.001)$, with a $20.69 \%$ cut off value, $77.78 \%$ sensitivity, and $76.19 \%$ specificity. Through the Pearson correlation analysis, IVC-CI and $\Delta$ SV were positively correlated with the coefficient $r=0.367(\mathrm{P}<0.05)$.

Discussion: As a rapid and noninvasive monitoring method, ultrasonic measurement of the respiratory variability of inferior vena cava in assessing the volume responsiveness of geriatric hip fracture patients can provide guidance for perioperative fluid management.

Prehosp Disaster Med 2019;34(Suppl. 1):s120-s121

doi:10.1017/S1049023X19002589

\section{Disaster and Mass Casualty Incident Responses by Doctor} Car

Dr. Masamune Kuno ${ }^{1}$, Kensuke Suzuki ${ }^{2}$, Dr. Kyoko Unemoto ${ }^{1}$, Dr. Takashi Tagami ${ }^{1}$, Dr. Fumibiko Nakayama ${ }^{1}$, Dr. Junya Kaneko ${ }^{1}$, Dr. Ken Saito ${ }^{1}$, Dr. Shin Sato ${ }^{1}$,

Dr. Chie Tanaka ${ }^{1}$, Dr. Reo Fukuda ${ }^{1}$, Dr. Saori Kudo ${ }^{1}$, Dr. Akiko Kitahashi ${ }^{1}$

1. Nippon Medical School Tama-nagayama Hospital, Tama, Japan

2. Nippon Sport Science University, Japan

Introduction: Ambulances with physicians, known as Doctor Car, and Tokyo DMAT are the two prehospital care systems responsible for medical team dispatch in the Tokyo area. While there are 25 designated hospitals for DMAT, Doctor $\mathrm{Car}$ is only available at four hospitals. Our hospital incorporates both systems. While the prehospital care system must be utilized at the time of disaster, Doctor Car was dispatched 418 times in 2017, and the use of DMAT is less than ten times per year.

Aim: To review the past disaster responses of our hospital.

Methods: The study reviews three cases where our hospital responded to mass casualty incidents and disasters with either Doctor Car or DMAT. The first case was the treatment of crush syndrome caused by a collapsed parking slope. It took more than 24 hours for the rescue, in which the team treated patients during transport and at the hospital. The second case was our response to a mass stabbing incident committed at a facility for the disabled. In collaboration with the onsite rescue team, we conducted triage, hemostasis, transfusion, etc. The third case was caused by a fire in a building under construction. We provided treatments like triage and tracheal intubation on the spot.

Results: Because paramedics are allowed to conduct only a limited amount of treatments, dispatch of the medical team to the site is effective.

Discussion: For a medical team to be effective at the dispatched site, the team must be accustomed not only to the specific need of medical care during disasters but also prehospital medical care, which may include the abilities to ensure safety during transport and on-site and adapt to the prehospital environment. Doctor Car is a useful way to realize such abilities.

Prehosp Disaster Med 2019;34(Suppl. 1):s121

doi:10.1017/S1049023X19002590
Disaster Education and Drills in Turkey: Do We Prepare Ourselves for Unexpected Disasters?

Mr. Volkan Ülker ${ }^{1,2}$, Ass. Prof. Dr. Özcan Erdoğan ${ }^{1}$

1. Bezmilaem Foundation University, İstanbul, Turkey

2. Sakarya University Research and Education Hospital, Sakarya, Turkey

Introduction: Turkey is vulnerable to many natural hazards, including earthquakes, landslides, floods, and terrorist attacks. The 7.1 magnitude Marmara Earthquake in 1999 resulted in over 18,000 deaths and estimated losses of over $\$ 28$ billion. The country's largest city, Istanbul, is located on the North Anatolian Fault and thus highly prone to earthquakes. It is estimated more than half of the population in the country are potentially seismically vulnerable. This vulnerability makes us ready for disasters. Turkey has advanced disaster risk management through initiating reforms to better manage and reduce disaster risk and strengthening institutions.

Aim: To overcome institutional fragmentation, the government established the Disaster and Emergency Management Presidency (AFAD) in 2009.

Methods: Assess the 2015 government adopted Turkey National Disaster Response Plan to guide all disaster and emergency response.

Results: In the last six years, Turkey has become one of the world's largest refugee-hosting countries. As of 2018, approximately 3.5 million Syrians under temporary protection have largely been integrated into cities, towns, and villages that stressing the infrastructure and increasing potential risk exposure. This situation makes us recognize disaster protection preparedness. We have many public and civil institutions to prepare society for unexpected situations. The main institution is the Disaster and Emergency Management Presidency. AFAD has many projects for youth, school children and all age groups of society. The second organization is the Red Crescent organization of Turkey. The other organizations are mainly National Medical Rescue Teams (UMKE), some university disaster clubs, and civil institutions like Beşir NGOs.

Discussion: These institutions give main disaster confidence education, main CBRN education, main fire-fighting education, camping life educations, orienteering, mobile oven, and kitchen facilities and drills. We have to raise awareness of the community about preparedness to disasters. We have to share lessons with the whole population for reducing social and economic loss.

Prehosp Disaster Med 2019;34(Suppl. 1):s121

doi:10.1017/S1049023X19002607

Disaster Medical Management of Pediatric and Perinatal Disaster Medical Liaison (PPDML) for Children and Pregnant Women in Osaka, Japan

Mr. Hideki Arimoto ${ }^{1}, M r$. Shinsuke Furuya ${ }^{1}$,

Ms. Kimiko Yamashita ${ }^{2}$, Mr. Kazuharu Tanaka ${ }^{3}$,

Ms. Tomoko Maruyama ${ }^{4}$, Ms. Muneyuki Takeuchi,

Ms. Kazuko Wada ${ }^{5}$, Mr. Kazubide Ogita ${ }^{6}$, Ms. Miho Misaki ${ }^{7}$, Mr. Akibiro Fuke ${ }^{1}$, Mr. Hiroshi Rinka ${ }^{1}$ 